\title{
Sociabilidades: uma Rede de Relações no Trabalho com o Lixo
}

\author{
Marília Veríssimo Veronese* \\ Sueli Maria Cabral** \\ Norberto Kuhn Junior***
}

\section{Resumo}

0 artigo analisa as representações construídas por um grupo de trabalhadores que, de alguma forma, estão entrelaçadas com o lixo, em termos de desvelar como articulam processos de sociabilidades e que sentidos atribuem ao trabalho com os resíduos. Com base na noção simmeliana de sociabilidade, tomamos a vida cotidiana enquanto jogo e arte, sendo que o estar-junto confere sentidos às coisas e às pessoas, agregando um modo de ser - ethos mesmo que particular e momentâneo, propiciando um sentir-junto às convergências das ações e à sinergia social. Foram realizadas entrevistas com vinte e oito trabalhadores organizados em uma cooperativa de reciclagem. As entrevistas foram analisadas a partir do método do Discurso do Sujeito Coletivo, proposta de organização de dados qualitativos de natureza verbal, com fundamento na teoria das representações sociais. Evidenciou-se uma rede de relações que fomenta estratégias e ações questionadoras, que combatem os problemas em um âmbito privado, mas igualmente no aspecto público de suas vidas, entrelaçando-os. Pois, quando estão unidos cotidianamente, lutam contra - não necessariamente vencem - 0 próprio estigma social a que são submetidos.

\section{Palavras-chave}

Sociabilidades. Catadores. Trabalho.

\footnotetext{
* Marília Verisimo Verone é Doutora em Psicologia Social pela Pontifícia Universidade Católica (PUC) - Rio Grande do Sul. Docente e pesquisadora do Programa de Pós Graduação em Ciências Sociais da Universidade do Vale dos Sinos - UNISINOS. Email: mariliavero@yahoo.com.br.

** Sueli Cabral é Doutora em Ciências Sociais pelo Programa de Pós-Graduação em Ciências Sociais da Universidade do Vale os Sinos. Docente da Universidade Feevale. Email: suelimariacabral@gmail.com.

*** Norberto Kuhn Junior é Doutor em Ciências da Comunicação pela Universidade do Vale do Rio dos Sinos; e docente e pesquisador no Programa de Pós-graduação em Diversidade Cultural e Inclusão Social e no Mestrado Profissional em Industria Criativa da Universidade Feevale. Email: nkjunior@feevale.br.
} 


\section{Abstract}

The article analyzes the representations created by a group of workers which, in some way, are intertwined with trash, in terms of revealing how the processes of sociability articulate and which meanings are attributed to the work with waste. Based on the simmelian notion of sociability, we face our daily lives as games and art, only the being-together gives meaning to things and people, incorporating a way of being - an ethos - even if it is private and momentary, fostering a feel-together to the converging of actions and the social synergy. Twenty-eight workers of a recycling cooperative were interviewed. The interviews were analyzed based on the method of the Discourse of the Collective Subject, which was proposed with the organization of qualitative data of verbal nature, founded on the theory of social representations. It became evident that there is a network of relationships which foment questioning strategies and actions, confronting the problems in the private as well as the public areas of their lives, intertwining them. Therefore, in their everyday union, they fight against - but not necessarily win - the very social stigma to which they are submitted.

\section{Keywords}

Sociability. Waste pickers. Work.

\section{Introdução}

O estudo que ora se apresenta toma como ponto central vidas estigmatizadas, aprofundando o estudo da tríade homem-lixo-trabalho enquanto figuras de desordem ${ }^{1}$. Busca-se a compreensão da vida cotidiana dos sujeitos em questão e o quanto esse cotidiano pode revelar um movimento em que a desordem se configura como agente de fortalecimento individual e coletivo. $\mathrm{O}$ foco está na tessitura de uma forma de estar-junto que se tornou um fundamento da sociabilidade presente, um vínculo que ganha a condição de processo de aproximação e estreitamento das relações entre os membros do grupo e destes em suas demais interações. Essas relações não são apenas utilitárias,

\footnotetext{
${ }^{1}$ Os estudos sobre a rede de significados que compõem a complexa tríade homem-lixo-trabalho teve iníicio com a pesquisa intitulada "Trabalhadores do Lixo, o Relato de Uma Pedagogia da Desordem", realizada em 2001, em uma perspectiva que explorou prioritariamente o aspecto pedagógico do trabalho e as possibilidades da construção de conhecimentos significativos que foram denominados conhecimento-emancipação.
} 
mas compõem uma sociabilidade compreendida como um fenômeno singular.

A pesquisa foi realizada com sujeitos que trabalham juntos, convivem e, em grande parte, sobrevivem dos resíduos sólidos urbanos, moradores da cidade de Esteio-RS, em bairros periféricos, comunidades de abrangência do programa governamental Territórios da $\mathrm{Paz}^{2}$ e (re)conhecidas pelas ausências de segurança, de saneamento básico e outros direitos de cidadania. Em tais espaços, a violência é vivenciada na realidade não apenas objetiva, mas igualmente simbólica.

Assim, tornou-se relevante durante o estudo um olhar atento aos lugares onde esses homens e mulheres moram e trabalham, o que, sem dúvida, confirmou a coexistência de elementos do passado e do presente ou de um passado reconstituído no presente, que vem impulsionando e fortalecendo diferentes formas de convivência e inserção na sociedade atual.

Organizado em uma cooperativa, a COOTRE - Cooperativa de Trabalho de Recicladores de Esteio -, o grupo, composto por aproximadamente trinta pessoas entre homens e mulheres, trabalha diariamente no Centro de Triagem pertencente à Secretaria Municipal de Meio Ambiente, na cidade de Esteio, Rio Grande do Sul.

No período em que o estudo de campo foi realizado (durante o ano de 2014), vinte e oito trabalhadores estavam na condição de cooperados. Esse é um número que oscila durante o ano, pois, apesar dos benefícios oferecidos, como alimentação, equipamento de segurança e renda mensal acima da média das cooperativas de resíduos sólidos, a atividade ainda é exaustiva, penosa e cercada por estigmas que lhe conferem um status socialmente inferior.

É, portanto, na intercessão de elementos objetivos e simbólicos que a reflexão se inicia, uma reflexão não apenas do que se constitui de concreto - a existência objetiva do homem/mulher, do lixo e do trabalho - mas igualmente das percepções e das representações que circundam esses elementos, as representações dominantes de moral, de valor, de insegurança, do certo, do errado, de gênero etc. Isso acaba por transformar o acontecer cotidiano em uma instância de alianças que influencia e é influenciada pelas

\footnotetext{
${ }^{2}$ O programa faz parte do PRONASCI, Programa Nacional de Segurança Pública com Cidadania. É um programa federal com gestão local. (BRASIL, 2015).
} 
interações sociais existentes, as quais propiciam uma sociabilidade que, balizada por um estar-junto, confere sentidos às coisas e às pessoas.

\section{A Concepção de Sociabilidade}

As possibilidades de compreensão do conceito de sociabilidade partem do pressuposto de que existem laços sociais que são tecidos nas manifestações cotidianas, nas quais o estar-junto se consolida por certa fluidez e instantaneidade.

Tais laços, mesmo que fluidos, possibilitam um apropriar-se do mundo a partir de maneiras, atitudes e ações que permitem efetivas conexões das interações e das relações sociais. Por conseguinte, o pensamento simmeliano sobre sociabilidade constituiu-se um ponto de partida importante para a compreensão da condição do estar-junto.

Simmel (2006) considera que a sociedade é uma realidade que possui duplo sentido: em uma instância, há a percepção imediata da existência que leva a cabo os processos de associação e que une os sujeitos. Em outra, existem os interesses ou impulsos dos sujeitos que motivam tal união, como os econômicos, os bélicos, os eróticos, os religiosos etc. Para satisfazer tais impulsos e alcançar os propósitos de cada um ou de todos através de um estado constante de correlação e teleologicamente determinado, os sujeitos produzem efeitos sobre outros, ao mesmo tempo em que os recebem (SIMMEL, 2006).

Tais processos são determinados pelo grau de sociação, ou modos pelos quais os fluxos de experiências vividas ganham forma e persistem para além dos conteúdos íntimos originais que os sujeitos possuem. Para o autor, a própria consciência possui uma base sociológica, que permeia as atitudes individuais e se manifesta nas relações com os outros, de acordo com seus próprios conceitos e preconceitos.

\section{Círculos Sociais}

Na obra Sociologia Simmeliana, em especial, no capítulo intitulado El cruce de los círculos sociales, o autor ressaltou que os círculos sociais aos quais os sujeitos pertencem se multiplicaram. O sujeito coloca-se em diferentes grupos - ou 
círculos sociais - como a família, o trabalho e os amigos e, no entrelaçamento desses círculos sociais, constitui-se. Para Simmel, a noção de individualidade está associada ao número de círculos nos quais cada pessoa interage.

Os sujeitos e suas formas de produção simbólica e material, portanto, são os resultados do processo de interações que eles constroem ao longo de sua vida nos diversos círculos sociais. E sua participação neles acaba por expandir uma face da individualidade geralmente não explorada, sendo que são os pontos de intersecção que se tornam determinantes para a construção e a compreensão da própria individualidade.

A pertença a distintos círculos sociais acaba por colocar em comunicação os diferentes papéis que o sujeito desempenha em sociedade; concomitantemente, seu entrecruzamento constitui não apenas sua individualidade, mas, igualmente, relações que acabam por dar forma à complexa estrutura do tecido social. A articulação teórica entre a filosofia, a psicologia e a sociologia e sua recusa em aceitar as fronteiras disciplinares permite a Simmel (2006) revelar uma sociologia que não se limita a uma perspectiva cujo objeto seja a vida dos sujeitos, mas formada a partir dela. Nessa perspectiva, a categoria sociedade é apreendida como um processo de interações duradouras já cristalizadas - como o Estado e a família - e as não tão organizadas e duradouras, pois, considerando-se que os sujeitos estão constantemente ligados uns aos outros, influenciando e recebendo influências, cria-se um laço social que se retroalimenta por eles mesmos, constituindo um processo de sociação que acontece por elementos tangíveis e não tangíveis.

Os laços de associação entre os homens são incessantemente feitos e desfeitos para que não sejam refeitos, constituindo uma fluidez e uma pulsação que atam os sujeitos, mesmos quando não atingem a forma de verdadeiras organizações. Que os seres humanos troquem olhares e que sejam ciumentos, que se correspondam por cartas ou que almocem juntos, que pareçam simpáticos ou antipáticos uns aos outros para além de qualquer interesse aparente, que a gratidão pelo gesto altruísta crie um laço mútuo indissolúvel, que um pergunte ao outro pelo caminho certo para se chegar a um determinado lugar, e que um se vista e se embeleze para o outro - todas essas milhares de relações cujos exemplos citados foram escolhidos ao acaso, são praticadas de pessoa a pessoa e nos unem ininterruptamente, sejam elas momentâneas ou duradouras, conscientes ou inconscientes, inconsequentes ou consequentes. (SIMMEL, 2006; p.17). 


\section{Sociação e Sociabilidade}

$\mathrm{O}$ autor acredita que as relações sociais estão ligadas a um sentimento comum a todos os homens e mulheres: a sociabilidade. Ressalta, contudo, que ela pode variar de intensidade segundo as qualidades pessoais daqueles com os quais nos relacionamos, intercambiando ideias, emoções e até objetos. Nesse sentido, seu pensamento sociológico traz, de forma proeminente, a questão das interações sociais que, para ele, constituem a base das relações sociais.

A sociedade só existe a partir dessas ligações entre os sujeitos; nesse processo, esses influenciam e são influenciados, consolidando, dessa forma, uma relação de troca e distinguindo-se de um simples conjunto de sujeitos. Trata-se, portanto, do princípio da reciprocidade de efeitos entre as ações individuais, fundamental na teoria simmeliana, pois é o que mantém as interações e, consequentemente, a existência da própria sociedade.

Assim, a partir do conceito de sociação, surge o de sociabilidade, que para Simmel (2006) vincula-se à ideia de que a vida social só existe no âmbito das formas sociais. Ou seja, a existência individual é um transitar habitual por um conjunto de formas fluidas, efêmeras ou fixas, que, ao serem responsáveis pelas interações dos sujeitos, acabam por representar a capacidade de criação do espírito humano.

Tomando por base as categorias sociológicas, defino então a sociabilidade como a forma lúdica de sociação, e - mutatis mutandis - algo cuja concretude determinada se comporta da mesma maneira como a obra de arte se relaciona com a realidade. (SIMMEL, 2006; p.65).

A sociabilidade estabelece-se mediante um jogo em que cada sujeito deve garantir ao outro aquele máximo de valores sociáveis (felicidade, autonomia, liberação, vivacidade) compatível com o máximo de valores recebidos por esse sujeito, imbuídos de valores intencionais. Nesse jogo, há uma atração que possui um duplo sentido: "não somente joga na sociedade aquele que a mantém externamente, mas com ele joga-se de fato a sociedade" (SIMMEL, 2006; p.72).

Os sujeitos como parte da sociedade vão estar pautados em um complexo conjunto de atitudes socialmente sancionadas, que vão permitir a efetivação das interações e das relações sociais; são os arranjos sociais que se configuram como artifícios de produção do meio social. Considerando as formas de sociabilidade, existe um nivelamento das posições sociais. A priori, 
as relações ocorrem em membros de classes sociais similares, pois implicam valores partilhados. Trata-se, nesse sentido, de uma relação construída com indivíduos que vivem e convivem com seus iguais, com proximidade espacial e conhecimento mútuo. São vínculos que transcendem a intimidade da casa, mas que propiciam o encontro mais estimado com o outro, fazendo dele uma fonte de segurança, mas igualmente de receios.

Desse modo, como já foi dito, a sociabilidade oferece um caso possivelmente único no qual o falar se torna legitimamente um fim em si mesmo. Por ser puramente bilateral - e, talvez, com a exceção da "troca de olhares", a forma de bilateralidade mais pura e sublime entre todos os fenômenos sociológicos -, ela se torna o preenchimento de uma relação que nada quer ser além de uma relação, na qual também aquilo que de resto é apenas forma de interação torna-se seu conteúdo mais significativo.

\section{Forma e Conteúdo da Sociação}

Simmel (2006) compreende a sociedade a partir de duas diferenciações básicas: forma e conteúdo. O conteúdo da sociação é o que existe no sujeito, tais como os impulsos, os interesses e as finalidades, que são, em síntese, os interesses, os fins e as motivações individuais, tratando-se do que é próprio do sujeito e que lhe permite causar efeitos sobre os outros e receber efeito dos outros. Ressalta-se, no entanto, que tais motivações se tornam sociais apenas quando presentes nos processos de interação. Tais conteúdos, por sua vez, concretizam-se na realidade social a partir das formas ou dos modos de interação entre os sujeitos.

A sociação é, portanto, a forma (que se realiza de inúmeras maneiras distintas) na qual os sujeitos, em razão dos seus interesses - sensoriais, ideais, momentâneos, duradouros, conscientes, inconscientes, movido pela causalidade ou teleologicamente determinados se desenvolvem conjuntamente em direção a uma unidade no seio da qual esses interesses se realizam. (SIMMEL, 2006; p.60-61).

Percebe-se, portanto, que, entre as formas e os conteúdos, há sempre um jogo, uma tensão constante e igualmente uma autonomia, na qual as formas passam a ter vida própria e não estão conectadas a um determinado conteúdo. E esse processo acaba por gerar o fenômeno da sociabilidade. 
Para o autor, interesses e racionalidade pouco estão envolvidos na noção de sociabilidade. São relações que têm como fim elas mesmas, sua existência está condicionada ao momento sociável e, quando muito, a sua lembrança. Não há propósitos objetivos nem resultados exteriores, a sociabilidade depende das personalidades envolvidas e do instante vivido. Entende-se, portanto, que o homem sociável só existe em relações sociáveis, nas relações de jogo social, nas conversações, que há uma "democracia da sociabilidade, mesmo entre aqueles socialmente iguais, é um jogo de cena. A sociabilidade cria, caso se queira, um mundo sociologicamente ideal: nele, a alegria do sujeito está totalmente ligada à felicidade dos outros" (SIMMEL, 2006; p.69). Ou seja, a única obrigação do sujeito é oferecer o máximo de valores sociais (alegria, vivacidade e similares) compatíveis com o máximo de valores que recebe. Trata-se de um estar-junto que, a partir de um eu que é plural, permite constituir laços sociais de ideias, sonhos e emoções partilhadas. Trata-se de uma sociabilidade que possui uma lógica transgressora da ordem racionalizadora e instrumental, vivenciada na dimensão que cria condições à participação e ao multicultural, experimentados e compreendidos também pelos sentidos. Assim, revela-se enquanto um terreno sobre o qual é possível entender o subterrâneo da dinâmica social, o que religa, a partir da lógica de interesses, impulsos e emoções que repousam em um tipo de ligação com o outro, que repousa na correspondência, no reconhecimento da proximidade.

Essa breve incursão sobre o tema sociabilidade não está, obviamente, completa, nem pretende esgotar um tema complexo, amplo e interdisciplinar. Apenas nos fornece alguns elementos teóricos para pensar o objeto em foco. Passamos agora ao estudo das interações e representações dos trabalhadores da COOTRE, que nos forneceram um rico registro empírico para análise. Iniciamos com breve descrição dos procedimentos metodológicos adotados na coleta e análise dos relatos dos vinte e oito trabalhadores entrevistados, para, na sequência, desvelar a tríade homem-lixo-trabalho através das categorias produzidas na análise, "o trabalho com o lixo" e "a reciprocidade do estar-junto".

\section{Imersão Etnográfica e o Método do Discurso do Sujeito Coletivo}

Com apoio na revisão bibliográfica realizada, nas observações participantes, nas entrevistas semiestruturadas e nas anotações no diário de campo, 
procuramos traduzir as representações produzidas entre trabalhadores, que impactam na constituição de suas identidades, nos processos de sociabilidades e nos sentidos do trabalho com o lixo. Ressalta-se que a lógica da pesquisa só pode operar a partir da interligação de elementos sociológicos, antropológicos, geográficos e socioeconômicos, conectando o empírico e o teórico, desenvolvendo uma elaboração analítica que destaca, separa e opõe, mas na qual não procede a redução e a disjunção (MORIN et al., 1997).

Assim, optou-se pelo paradigma qualitativo, uma vez que, sob essa perspectiva, é possível compreender de forma singular atitudes, comportamentos, opiniões e atributos do contexto pesquisado, avaliando aspectos emocionais e intencionais, implícitos nas opiniões dos sujeitos da pesquisa e dada a complexidade do objeto de estudo. Entendeu-se, igualmente, ser necessário fazer uso dos pressupostos da etnografia como uma possibilidade de desvelar as representações próprias ao campo, o que exige que o observador vá além dos discursos e observe os rituais (formais ou não) do grupo analisado. Sendo assim, a etnografia pode oportunizar o reconhecimento e conhecimento, dando a inteligibilidade necessária para a compreensão. Sobre etnografia, em especial a urbana, Magnani (2002; p.18) afirma que

... o que se propõe é um olhar de perto e de dentro, mas a partir dos arranjos dos próprios atores sociais, ou seja, das formas por meio das quais eles se vêm para transitar pela cidade, usufruir seus serviços, utilizar seus equipamentos, estabelecer encontros e trocas nas mais diferentes esferas - religiosidade, trabalho, lazer, cultura, participação política ou associativa etc. Esta estratégia supõe um investimento em ambos os polos da relação: de um lado, sobre os atores sociais, o grupo e a prática que estão sendo estudados e, de outro, a paisagem em que essa prática se desenvolve, entendida não como mero cenário, mas parte constitutiva do recorte de análise. É o que caracteriza o enfoque da antropologia urbana, diferenciando-o da abordagem de outras disciplinas e até mesmo de outras opções no interior da antropologia.

As entrevistas foram analisadas a partir do método do Discurso do Sujeito Coletivo (DSC), que é uma proposta de organização e tabulação de dados qualitativos de natureza verbal, obtidos de depoimentos/entrevistas, com fundamento na teoria das representações sociais de Serge Moscovici (2003) e seus pressupostos sociológicos. Essa metodologia tem como ponto de partida depoimentos coletados por entrevistas e "visa expressar o pensamento de 
uma coletividade, como se esta coletividade fosse o emissor de um discurso" (LEFEVRE; CRESTANA; CORNETTA, 2003; p.70).

O Discurso do Sujeito Coletivo tem os depoimentos como matéria-prima, sob a forma de um ou vários discursos-síntese escritos na primeira pessoa do singular, expediente que visa expressar o pensamento de uma coletividade, como se essa coletividade fosse o emissor de um discurso. A proposta consiste essencialmente em analisar os depoimentos coletados e, posteriormente, interconectá-los com a fundamentação teórica desenvolvida. Trata-se de uma abordagem socioantropológica, porque assim é possível compreender as representações sociais como expressão de referências de uma coletividade ${ }^{3}$. Lefèvre e Lefèvre (2005; p.25) conceituam o método como uma

estratégia metodológica para descrever o sentido dos discursos presentes em pesquisa de representação social, pois utiliza-se, entre outras, das figuras metodológicas da ideia central e das expressões chaves. O objetivo aqui é mostrar como a inter-relação entre essas duas figuras contribui para descrever, de maneira adequada, o sentido dos discursos presentes em pesquisa sobre representações.

De acordo com seus criadores, o DSC possui três figuras metodológicas centrais, a saber: expressões-chave, ideias centrais e ancoragem. Expressões-chave (ECH) são trechos do discurso coletado que acabam por revelar a essência do conteúdo das representações ou das teorias subjacentes a elas. As expressões são parte essencial da análise e constituem os recortes do discurso. Ideias Centrais (IC) são a descrição sintética do sentido das palavras do entrevistado; não constituem, contudo, uma interpretação, mas uma descrição, revelando o que foi dito. No que diz respeito à Ancoragem, segundo os autores, algumas ECH não remetem a uma IC, mas à manifestação de uma teoria, ideologia ou crença em que os entrevistados acreditam ou que professam. Trata-se de uma afirmação genérica do enunciador do discurso para enquadrar uma situação específica. Ressalta-se que todo discurso possui uma ancoragem, pois traz

\footnotetext{
${ }^{3}$ Não se trata aqui de resgatar as representações coletivas de Durkheim (1994), uma vez que estas são muito abrangentes e pouco flexíveis para darem conta da produção do pensamento na sociedade atual. Busca-se, todavia, compreender o posicionamento subjetivo dos sujeitos a partir de espaços sociais que encadeiam fenômenos interativos, frutos de processos sociais do cotidiano do mundo contemporâneo, a partir da teoria de Moscovici (2003) e de outros que a desenvolvem.
} 
uma ideia básica que sustenta o discurso, os valores que estão embutidos na fala, o que está subjacente ao cotidiano. Todo processo de análise do DSC considera o discurso de sujeitos que compartilham um espaço social ou de crenças e valores comuns indissociáveis do pensamento possível de ser coletivo - mesmo que, em uma temporalidade determinada - e procura compreendê-la sem fazer mutilações em favor de uma teoria ou outra. Nesse sentido, o DSC configura-se como um sistema de interpretação da realidade dos participantes, das relações estabelecidas por eles no contexto social a partir de suas falas.

Considerando-se tais premissas, o processo de coleta de dados iniciouse no primeiro semestre de 2014. Em termos gerais, o processo etnográfico percorreu o caminho da percepção, conhecimento e interação entre pesquisadores e sujeitos, criando os elos necessários entre a ética e a estética, o público e o privado, a ordem e o caos. Potencializou-se, assim, a apropriação de uma interpretação possível das coisas da vida cotidiana e, entre o que foi dito e o que ficou silenciado, procurou-se dar visibilidade aos diferentes sentidos, às diferentes representações e concepções existentes no espaço pesquisado. As histórias relatadas pelos sujeitos e os momentos comuns compartilhados permitiram entrar em um universo repleto de elementos tangíveis e não tangíveis. Essa riqueza favoreceu maior compreensão dos discursos, que acabaram por representar as vozes de um grupo de sujeitos infinitamente interessante, complexo e, como diria Friedrich Nietzsche (2003), humano, demasiado humano.

Tal etapa configurou-se a partir da curiosidade e da flexibilidade (dias de visita, tempo de visitação e conversas), o que possibilitou a construção de um diário de campo (DC - que aparece, aqui, na forma de citação). Esse diário constitui-se para além de uma acumulação de anotações, pois permitiu que pequenos acontecimentos se mostrassem reveladores de importantes signos, favorecendo uma percepção mais sensível e menos mutilada da realidade investigada. Tem-se, como resultado desse processo, vínculos estabelecidos a partir do duplo olhar: o da estranheza (ações cognitivas que permitem uma compreensão pelo exterior) e o da identificação (ações cognitivas que permitem uma compreensão pelo interior), permitind o certa inteligibilidade do fenômeno, em uma perspectiva que une múltiplos elementos: coisas, signos, símbolos ou discursos, sempre em uma postura dialógica do que estranha e identifica. É o que vai se verificar nas considerações a seguir.

O DSC foi utilizado como recurso metodológico e expositivo, para compor um discurso, finito e temporal, que contemporizou o sentido comum 
das falas dos sujeitos entrevistados. O resultado final não é uma narrativa comumente vista, ou seja, um texto coeso com início e fim. Trata-se antes de uma compilação das Expressões-chave (ECH) e Ideias Centrais (IC), que foram agrupadas por categorias.

\section{Trabalho com o Lixo e a Reciprocidade do Estar-Junto}

Vimos que a noção de sociabilidade nos permite enaltecer a vida cotidiana enquanto jogo e arte, sendo que o estar-junto com o outro confere sentidos às coisas e às pessoas, agregando um modo de ser (ethos), mesmo que particular e momentâneo, propiciando um sentir-junto às convergências das ações e à sinergia social, o que possibilita desvelar mais da tríade homem-lixo-trabalho. Para o recorte proposto nesse artigo, tomamos as seguintes perguntas e suas respectivas categorias emergentes: "Por que e como iniciou o trabalho na COOTRE?", da qual resultou a categoria "trabalho com o lixo: a estação possível"; e a pergunta "Qual sua relação com seus colegas de trabalho? O que eles significam para você??", que resultou a categoria "Reciprocidade do estar-junto".

\section{Trabalho com o lixo: a estação possível}

Uma vez reunidas todas as respostas à questão "Por que e como iniciou o trabalho na COOTRE?" e aplicados os procedimentos de organização dos dados conforme descrito, chegamos à categoria Trabalho com o lixo: estação possível, em uma clara referência a um local onde, apesar dos estigmas, dignidade e esperança se entrelaçam no cotidiano.

Os entrevistados já estiveram ligados ao trabalho assalariado, formalmente ou não, seja no âmbito fabril ou doméstico; contudo, a baixa escolaridade, antecedentes criminais e, em alguns casos, o preconceito social e práticas discriminatórias contra pessoas gays, lésbicas, travestis e transexuais, favoreceram a entrada dos sujeitos na COOTRE. Sua permanência na atividade - ainda que repleta da percepção de dignidade, é carregada de estigmas a ela atribuídos - justifica-se pelo fato de que eles não acreditam que haja uma opção real de trabalho com uma carga menos penosa, física e emocional.

Olha eu vivi de prostituição, mas na rua não estava dando mais. A rua é assim: um dia dá, outro dia não dá. Foi onde uma amiga 
minha falou assim: "Ah, tem a reciclagem lá do morro, olha, é no meio do lixo, tu é nojenta!" E realmente eu sou nojenta. Eu estava precisando, tu encara entendeu? Foi onde eu fui e me surpreendi comigo mesma, tu nunca foi lá, não é? É horrível, um verdadeiro lixão com comida junto, tudo o que tu imaginar [...] Lá eu ganhava $\mathbf{R} \$ 200,00$ por semana, descontava 30 reais da Van, ficavam 170 reais. Então falei com uma amiga e ela falou com a coordenadora. Fui aceita e eu estou aqui. Mas não é fácil e eu quero mais. Quero voltar a estudar técnico de enfermagem. (Entrevistada X, fev/14).

A precariedade na execução das atividades - menor quando comparada com outras sedes de associações ou cooperativas - é quase palpável. As instalações elétricas são inapropriadas (extensões das extensões) e, em dias de chuva, há goteiras próximas ao pequeno e perigoso universo de fios e suas imbricadas conexões. A esteira é muito alta, dificultando o processo de triagem do material recebido. Sua estrutura, portanto, não oferece qualidade na relação máquina versus operador, o que, em médio prazo, poderá causar danos à saúde desses trabalhadores. Os equipamentos de proteção individual ou EPI's são fornecidos, mas pouco utilizados, uma vez que, para muitos, esses equipamentos mais atrapalham do que ajudam no cumprimento das tarefas. O trabalho é árduo e realizado de segunda a sextafeira regularmente e, quando necessário, também aos sábados. A triagem do material, a pesagem e o enfardamento são trabalhos intensos, o cheiro do ambiente é de lixo e o cansaço, perceptível. Nenhum dos associados/ cooperados contribui para o INSS, dependem exclusivamente da assistência médica pública e, nos recentes exames médicos realizados - fruto de uma parceria inédita entre a COOTRE, Prefeitura de Esteio e uma Unidade Básica de Saúde do município - nenhum deles está em condições de saúde consideradas plenamente satisfatórias, apresentando variados problemas. Esses são apenas alguns elementos que exemplificam a precariedade do trabalho e a condição vulnerável em que os trabalhadores da COOTRE se encontram. Esse cenário pode ser compreendido melhor a partir de Robert Castel (2003), que afirma que é difícil estabelecer uma clara separação entre a precariedade e a vulnerabilidade, uma vez que ambas estão entrelaçadas. Apesar de esse autor não se referir especificamente ao Brasil, suas proposições constituem-se subsídios importantes para a compreensão do nosso contexto. Nascidas no seio de movimentos econômicos excludentes, a precariedade e vulnerabilidade geraram, em seu percurso, uma dinâmica social que resultou em um processo de desfiliação, constituído de frágeis vínculos dentro das 
estruturas sociais.

Os sujeitos entrevistados foram atingidos por esse fenômeno e, portanto, em algum momento de suas vidas, perceberam-se fora dos "circuitos de trocas produtivas", tornando-se "inúteis" nos espaços socialmente aceitáveis, que se articulam pela interdependência funcional entre seus membros produtivos. O grupo, dessa forma, não apenas estava em uma condição de desfiliação, de flutuação dentro da estrutura social - inclusive, em alguns casos, alguns sujeitos encontram-se em desfiliação sociofamiliar - mas, igualmente está separado por uma linha abissal (SANTOS, 2007), que fomenta nele uma condição de vida repleta de desconfiança e de insegurança em razão de seu suposto status de inferioridade.

Eles são os outros que estão "do lado de lá" dessa linha simbólica que separa os cidadãos, os incluídos no mundo do trabalho, dos não cidadãos e dele excluídos. Contudo, ainda resta perguntar: mas quem são esses que estão no lado de lá? Quem são os que possuem uma existência considerada tão desqualificada que são metaforicamente considerados inexistentes? De modo geral, são sujeitos que possuem algumas características comuns: são destituídos de recursos materiais e, por vezes, simbólicos; possuem dificuldades de acessar seus direitos sociais - em relação à saúde, à educação, à cultura e ao lazer; normalmente, estão em uma zona de invisibilidade; e, por terem baixo poder aquisitivo, são considerados pobres e dificilmente encontram-se próximos a um trabalho de boa qualidade, compondo o exército de uma sub-humanidade moderna.

Destaca-se que dezoito dos vinte e oito entrevistados para este estudo declararam que não completaram o Ensino Fundamental; destes apenas oito terminaram o $5^{\circ}$ ano; os demais frequentaram por apenas um ou dois anos os bancos escolares. Mesmo assim, vale o destaque para as respostas "Eu sempre trabalhei em reciclagem, no lixão mesmo. Sem estudo e sem dinheiro tem que ir para o lixo mesmo"; "Antes eu trabalhei como assalariada, mas foi por pouco tempo, e eu sabia que eu não iria conseguir de novo. Não tenho estudo, não tenho profissão e não me esforcei para ter uma" e "Eu não sou boa para trabalhar com outra coisa, só com o lixo mesmo". Tais fragmentos do DSC sintetizam alguns elementos fundantes do processo de inserção do grupo na ARCA/COOTRE, e a leitura atenta desvela que o que está presente são sentidos muito mais amplos que a própria pergunta.

Sentimentos de incapacidade e inferioridade permeiam todo o discurso, oriundos talvez da baixa escolaridade ou de outras contingências vividas; os sujeitos compreendem, de modo geral, que são os únicos responsáveis pela 
recusa do mercado em (re) admiti-los e, portanto, o que lhes cabia (ou o que lhes cabe?) era (é?) o trabalho com o lixo. Na perspectiva dos entrevistados, tal condição de sobrevivência não decorre do fato de serem vítimas de uma sociedade excludente ou, no mínimo, corresponsável pelas decisões tomadas no decorrer de sua vida. Inicialmente - e esta palavra deve ser destacada o trabalho com o lixo é condição de merecimento - ou a ausência deste, pois não acreditam que são "bons o suficiente" para realizar outro tipo de atividade.

Entende-se que tal leitura é o resultado de um esforço não apenas de entenderem, mas de se ajustarem à condição existente. Como anotado em uma das passagens do diário de campo construído no decorrer da pesquisa:

o grupo acredita que atualmente o trabalho com o lixo é bom, mas percebe-se que todos se referem a esta atividade não como uma opção, mas uma condição. A conversa na hora do almoço foi esclarecedora. Uma das mulheres afirmou que estava aqui porque era o que havia sobrado para ela nesta vida (DC, abril/2014.).

O que deve ser destacado é que sujeitos empobrecidos têm sido levados a conseguir alternativas de geração de trabalho e renda, seja através de iniciativas autônomas, seja através de coletivos organizados, herdeiros de gerações de igualmente empobrecidos, sem qualificação; preconizam um sentimento de inferioridade e desvalorização que acaba influenciando suas identidades. Igualmente, a partir das respostas apresentadas e das relações expressas pelos entrevistados, verifica-se que há outra base comum: quase a totalidade dos entrevistados foi para a COOTRE em função da atual presidente da cooperativa. Trata-se da líder do grupo, uma ativa liderança comunitária e uma conselheira religiosa.

A R. me mostrou que eu ia mudar minha vida. Trabalhar na COOTRE é trabalhar com a R. e, onde ela for, eu vou e o T. vai junto (ENTR 02, maio/14).

A liderança da presidente é forte técnica e administrativamente, mas há, em seu entorno, uma "aura messiânica”. Sua autoridade não está apenas no aspecto profissional. Trata-se de uma autoridade que também é espiritual. Seu alcance não é apenas nos trabalhadores da COOTRE, mas igualmente na comunidade adjacente à sua casa. Não há valores financeiros envolvidos, mas gosta que tudo seja feito da sua forma e no seu tempo (DC, abril/2014). 
As interações existentes, que compõem o cotidiano do trabalho, são sempre costuradas, fomentadas e, às vezes, construídas pela líder do grupo. Reuniões no horário do almoço são comuns, discussões coletivas sobre o enfrentamento dos problemas e a ampliação dos benefícios para todos estão sempre em pauta. Trata-se, portanto, de um processo relacional e simbólico, de proteção, de alianças e de laços sociais, vínculos que tangenciam o sofrimento e a desilusão, mas igualmente a esperança. Vale destacar, igualmente, algumas ideias presentes nos discursos que apontam em direção ao que Maffesoli (1996) denomina estética social. Para o autor, é na necessidade de pertencer que o laço social se constitui; trata-se de uma potência que cria a solidariedade e que favorece a fusão.

\section{Reciprocidade do estar-junto}

O Discurso do Sujeito Coletivo, formulado a partir das narrativas em torno das perguntas "Qual sua relação com seus colegas de trabalho? O que eles significam para você??", resultou na categoria de análise reciprocidade do estar-junto.

Propomos pensar essa categoria a partir das contribuições de Simmel (2006), em especial no que se refere à sociabilidades, pois as narrativas mostraram que existem relações claramente construídas e desenvolvidas a partir de um arquétipo social que sustenta as estruturas lá edificadas. Para dar conta das formas de sociação, o autor utiliza a noção de arquétipo sociológico, caracterizado, afinal, por um pensamento relacional. As construções subjetivas, os imaginários e suas modalidades de partilha são parte do repertório de modelos, ou arquétipos, que determinam a relação com o outro e com o espaço-tempo. Mas, no contexto investigado, o que seriam arquétipos? Os arquétipos estão no cerne dos simbolismos de diversas civilizações, estão presentes nos mitos, nas lendas, nos contos de fadas e até em obras de arte. A priori, trata-se de um fenômeno intuitivo, motivador de mudanças e/ou de identificação.

Eles são minha família. Eu sou mais gente perto deles. A gente briga, fala alto, mas todo mundo fica bem no final. É sempre bom estar aqui apesar de, às vezes, ser ruim. Dá para entender? Às vezes, a gente briga, mas depois fica tudo bem. É igual uma família mesmo. Às vezes, a Rita tem que puxar a orelha da gente, mas aqui eu não tenho receio de ser o que eu sou, eu falo de tudo, não só trabalho. Eles me apoiam quando estou triste e eu faço a mesma coisa com eles. Quando alguém está doente, nós ajudamos, 
quando precisa de apoio, nós estamos lá. A relação é boa e eles significam tudo para mim, eles são a minha família. (Entrevistada L, fev/2014)

São como uma família. Sabe, antes de vir trabalhar aqui eu tinha um monte de preconceito, por exemplo, com 'bibas', hoje não, antes de eu conhecer aquela bibona ali, eu até tinha um pouco, o Junior, sabe qual é? Quando eu cheguei aqui, fiquei até, meio assim, mas conversando com a gente, ele mostrou respeito, de não se passar nem nada, a gente foi dialogando, dialogando..., eu fui abrindo a mente pra isso também. (Entrevistada R, maio/2014).

Este trabalho faz com que a gente abra a cabeça para muitas coisas e para muitas pessoas. A gente se torna diferente, então passa a aceitar mais as pessoas pelo que elas são, não pelo que elas podem dar para você. A maioria não tem nada mesmo a não ser o que passa no coração. (Entrevistada M, abril/2014)

"Somos uma família" foi uma das expressões mais utilizadas pelo grupo, e não se pode esquecer que a família possui um lugar privilegiado na construção social da realidade, sendo lócus da constituição de importantes arquétipos e mitos sociais. Na tradição do pensamento social brasileiro, muito foi discutido sobre o entrecruzamento das esferas familiares - privada - e públicas, como Estado e local de trabalho. Segundo Itaboraí (2005), autores como Gilberto Freyre, Sérgio Buarque de Holanda e Nestor Duarte procuraram demonstrar como a família patriarcal favoreceu laços de dependência interpessoal que acabaram estendendo-se para a esfera pública, caracterizando, dentre outros elementos, a cultura ibérica da qual somos herdeiros. Contudo, nos parece aqui que a vinculação do grupo de trabalho com a ideia de família trazida pelos entrevistados também se deve a outros fatores de ordem psicossocial presentes na experiência desses catadores.

Uma vez que muitos dos sujeitos tiveram vínculos familiares interrompidos, parece-nos que o grupo ocupa um lugar de afeto que recupera vivências importantes para eles, fazendo emergir aspectos interessantes da categoria do estar-junto. Para Saraceno (1997), a família - que possui formas diferentes na sociedade - é um espaço simbólico e historicamente construído. A autora afirma:

O espaço ao mesmo tempo físico, relacional e simbólico aparentemente mais conhecido e comum, a ponto de ser usado como metáfora para todas as situações que têm a ver com 
espontaneidade, com a naturalidade, com o reconhecimento sem necessidade de mediação - «somos como uma família», «uma linguagem familiar», uma «pessoa da família» -, a família revela-se como um dos lugares privilegiados de construção social da realidade, a partir da construção social dos acontecimentos e relações aparentemente mais naturais (1997; p.5).

Assim, a partir da ideia de que "somos como uma família", que surge a partir das interações afetivas do e pelo grupo, percebe-se um prazer do estar-junto, que se constitui de uma emoção compartilhada, arquitetada no cotidiano do trabalho, mas que, em alguns casos, extravasa o espaço da cooperativa. Portanto, há uma linha muito tênue que separa o público trabalho, cooperativa, políticas de reciclagem - e o privado - casa, família, comunidade de entorno. Em "somos como uma família”, está presente um sentimento comum, uma forma comunitária que, apesar das inúmeras singularidades - e de suas próprias individualidades - possui um sentido de pertencimento que orienta os sujeitos pesquisados.

Destaca-se que o estar-junto desenvolvido pelo grupo é um valor central, e, apesar de talvez pouco comum, mostra que foram capazes de construir vínculos relacionais denominados por eles como familiares, influenciados diariamente por brigas, pela carga de atividade elevada, pelo material insuficiente, pela rotatividade, pelos afetos e desafetos, que geram sociabilidades e solidariedades, que acabam por estipular ou orientar condutas a serem seguidas. Por exemplo, apesar dos conflitos, a ajuda diante de problemas financeiros ou de saúde é uma rotina cotidiana para o grupo. A ajuda mútua é elemento fundamental em suas vidas diárias e algo que sustenta suas trajetórias pessoais.

Nos depoimentos coletados (de homens e mulheres), há sempre alguma referência que sublinha a importância da R., presidente da cooperativa. Ela tem sido suporte fundamental nas relações que são estabelecidas, uma mãe para todos. Ao que tudo indica, o grupo respeita as inúmeras intervenções de R. em suas vidas. Chama a atenção, em especial, sua atuação nos finais de semana, pois mantém um firme cuidado dos membros de sua família além-trabalho, como ela mesma denomina, uma postura firme que, com criatividade (visitas, jantares, roda de chimarrão, etc.) e solidariedade, fortalece o conjunto, principalmente, por meio de um estar-junto entre todos os membros.

Cabe destacar o emprego do conceito de estar-junto aqui utilizado: ele remete a um esforço que privilegia o sensível, o que liga os sujeitos uns com 
os outros, homens e mulheres que, em sua maioria, vivenciaram e que ainda vivenciam uma expressiva fragilidade de vínculos sociais. Estar-junto, portanto, permite o fortalecimento desses vínculos, na medida em os sentimentos e as experiências são partilhados.

As conversas, no horário do almoço e mesmo durante a execução das atividades, são muito particulares, quase invasivas. Uma das cooperativadas estava falando dos seus problemas conjugais com uma forte riqueza de detalhes; outro, dos problemas financeiros, considerando que os valores conquistados este mês estão abaixo da média da cooperativa, e outro de quanto a sua filha adolescente começou a 'problemar'. Mesmo estando nós presentes, não há qualquer indício de inibição. A troca de experiências é rica. Cada qual possui uma história para contar sobre o tema abordado (DC, junho/2014- pesquisadora).

Para Maffesoli (1996), as relações sociais estabelecidas no trabalho, na família, durante o lazer, ou seja, na ordem da vida, não são guiadas apenas por um objetivo a ser conquistado, delimitado por uma lógica econômica ou moral. Elas são estruturadas por laços sociais que tanto constituem, como são constituídos, por aqueles que elaboram um modo de ser, um ethos social, em que o "aqui e o agora", estão sempre em movimento e nunca são permanentes, ocupam um valor importante. Esse movimento é denominado pelo autor "ética da estética".

Decididamente, a estética (aisthesis), o sentir comum, parece ser o melhor meio de denominar o 'consenso' que se elabora aos nossos olhos, o dos sentimentos partilhados ou sensações exacerbadas: 'Cum-sensualis'. [ ... ] Parece, de fato, que uma estética descompartimentada permite compreender esse estarjunto desordenado, versátil e completamente inatingível sem isso: a socialidade (MAFFESOLI, 1996; p.13).

Assim, a ideia do estar-junto remete à noção de uma emoção estética, ou seja, uma emoção que não é mero fenômeno psicológico, mas funciona como "cimento", matéria-prima para a fusão de múltiplos valores, inclusive heterogêneos e, sem ser uma unidade, é capaz de formar, mesmo que de forma provisória e contraditória, certa unicidade.

A conversa hoje ficou na questão política e religiosa. Os diálogos mostram as diferentes posições. Religião e política entraram 
como prato principal no horário do almoço. Chama a atenção a cooperativada que, apesar de ser evangélica 'de verdade' - como ela mesma se denomina - não aprova o discurso preconceituoso de um dos candidatos evangélicos e a razão disso são, segundo a mesma, os amigos da COOTRE, que expressam claramente suas orientações sexuais, 'as bibas', como são denominados. Pelo menos por ora, mais forte que a fala do pastor é a amizade que os une (DC, novembro/2014).

Ressalta-se a fala da entrevistada que, aos 24 anos, é responsável pela sua família. O companheiro, os filhos e a mãe dependem dela para sobreviver. Para ela, a relação estabelecida com os colegas a equilibra, pois enfrenta uma dificuldade ainda maior: a luta com o tráfico, com o qual seu companheiro não quer mais se envolver após ter saído, recentemente, da prisão. Além disso, seu irmão mais novo cumpre pena no sistema prisional. Destaca-se, em suas respostas, a presença solidária do grupo, que se reúne para buscar ajuda e soluções viáveis para os problemas da colega. Essa característica, o estímulo e a procura de soluções para os problemas em conjunto, se não com todos os cooperativados, com a sua maioria, propicia uma integração a partir de uma solidariedade possível, um processo de reciprocidade e, por que não dizer, uma aprendizagem frente a situações impostas no cotidiano.

Evidencia-se, igualmente, uma rede de relações que fomenta estratégias e ações questionadoras, que combatem os problemas em um âmbito privado, mas igualmente no aspecto público de suas vidas. Pois, quando estão unidos, combatem - não necessariamente vencem - o próprio estigma social a que são submetidos "pela sujeira que os cerca e neles penetra, por sua existência em contato com imundícies, que não têm tempo nem meios para afastar de si e que sua própria educação não os ensinou a temer" (CORBIN, 1987; p.192).

Dessa forma, esses sujeitos, no convívio com as dificuldades, acabam tecendo um movimento transformador e organizador em suas vidas, efetuando mudanças que, por vezes, transcendem a ordem da realidade "para além de sua própria esfera e de seu ambiente, alterando-a a partir de sua dimensão ética, que irá nortear os seus valores" (PETRAGLIA, 1995; p.59). Sendo assim, a condição do estar-junto é a reciprocidade que se estabelece a partir do desordenamento da produção e reprodução - material e simbólica - das experiências individuais e coletivas. 


\section{Considerações Finais}

Conforme percebido ao longo da análise, atualmente a geração de trabalho e renda é apenas um dos motivos da permanência desses sujeitos no local de trabalho. O convívio existente entre eles fomentou a partilha de emoções e sensações, um estar-junto detentor de uma força capaz de oportunizar participações mais ativas diante dos problemas enfrentados no cotidiano não só do trabalho, mas de suas vidas como um todo. O espaço de trabalho, portanto, é mais um elemento que ajuda a clarear e compreender a tríade homem-lixo-trabalho. É um feixe de luz que contribui com sua tradução: a autoestima, o cuidado com o outro, a noção de igualdade e segurança constituem um lócus ético e estético que propicia uma (re) ligação a partir de uma ótica da emoção (MAFFESOLI, 1996).

Essa emoção conduz a um novo tipo de ligação com o outro, que repousa na correspondência, no reconhecimento daquele que está próximo. Nessa perspectiva, a sociabilidade enaltece a vida cotidiana enquanto jogo e arte, sendo que o estar-junto com o outro confere sentidos às coisas e às pessoas. O lixo, apesar de descartável e desagradável, é também renda, propicia uma "família", une e dá sentido à vida. Sentidos contraditórios, por certo; ao mesmo tempo em que a ele dedica-se quem "não estudou", ou "não fez por merecer" algo melhor, ele pode "salvar" vidas que seriam totalmente desperdiçadas pela precariedade: da prisão, da violência e mesmo da morte precoce. A rede de relações ativada pela produção das sociabilidades traz ambiguidades, ambivalências: apesar de o trabalho com o lixo ser a estação do possível, o que sobrou para eles, também propicia vivências que resgatam afetos desfeitos, constroem parcerias inusitadas, propiciam transformações na visão de mundo (como a catadora que tinha preconceito contra homossexuais e abandonou-os ao conviver com o colega da cooperativa que assumia tranquilamente sua orientação sexual).

O campo representacional dos sujeitos é complexo, mas as constelações de sentido incluem fortemente os vínculos sociais como esteios de sua sobrevivência e de sua luta por uma vida digna. A sociação, a prática e a fruição do estar-junto é cotidiana, e acaba formando vínculos de maior estabilidade, que assumem grande importância na vida dos sujeitos. A ocorrência da fluidez e o desfazimento de laços, característicos da perspectiva simmeliana, estão presentes, por certo; há certo ir e vir de associados que, vez por outra, saem para tentar um emprego, voltam eventualmente para atividades de risco, unem-se a outros grupos cooperativos em outros locais, 
tentam retornar à cooperativa; mas, enquanto permanecem na COOTRE, esse cotidiano de estar junto, esse vir a ser da vida social que experimentam lhes confere sentidos dignificantes, de acolhimento e sustentação. Afetam e são afetados continuamente na interação que os constitui como sujeitos.

Há uma combinação simultânea de "aproximações" e "afastamentos", conforme Simmel, sempre presente nas sociedades modernas, e o estar mais próximo ou estar mais longe é um jogo que, se não totalmente livre de determinantes socioeconômicos, como a pobreza e a precariedade, é jogado por esses sujeitos nas trajetórias que experimentam, constituindo em seu contexto, o socius que faz deles membros de uma sociedade.

\section{Referências}

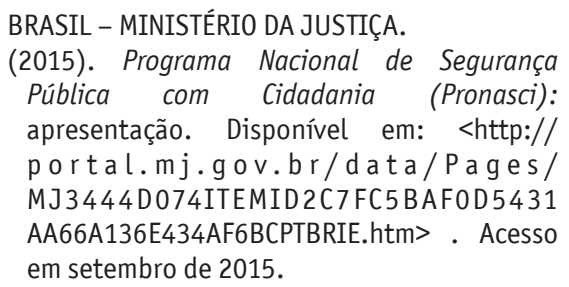
apresentação. Disponível em: <http:// portal.mj.gov.br/data/Pages/ MJ3444D074ITEMID2C7FC5BAF0D5431 AA66A136E434AF6BCPTBRIE.htm> . Acesso em setembro de 2015.

CABRAL, Sueli Maria.

(2001). Trabalhadores do lixo: o relato de uma pedagogia da desordem. Dissertação de Mestrado em Educação apresentada à Universidade Federal do Rio Grande do Sul.

CASTEL, Robert.

(2003). As metamorfoses da questão social: uma crônica do salário. 4. ed. Petrópolis: Vozes.

CORBIN, Alain.

(1987). Saberes e Odores. 0 olfato e o imaginário social nos séculos dezoito e dezenove. São Paulo: Companhia das Letras.

DURKHEIM, Emile.

(1994). As regras do método sociológico. 11. ed. São Paulo: Ed. Nacional.

GARCIA, Carmen Giménez.

(1977). Estudios sobre las formas de socialización by Georg Simmel. Revista española de la opinión pública, n. 49; p. 201208.
ITABORAÍ, Nathalie Reis.

(2005). A família colonial e a construção do Brasil: Vida doméstica e identidade nacional em Gilberto Freyre, Sérgio Buarque de Hollanda e Nestor Duarte. Revista ANTHROPOLÓGICAS, v. 16, n. 9; p. 171-196.

LEFEVRE, Ana Maria; CRESTANA, Maria Fazanelli; CORNETTA, Vitória Kedy.

(2003). A utilização da metodologia do discurso do sujeito coletivo na avaliação qualitativa dos cursos de especialização ‘Capacitação e Desenvolvimento de Recursos Humanos em Saúde-CADRHU'. Saudesoc, São Paulo, v. 12, n. 2, Dec.

LEFÈVRE, Fernando; LEFÈVRE, Ana Maria. (2005). A soma qualitativa. Disponível em: <http://www.fsp.usp.br/quali-saude> Acesso em 12 de maio de 2012.

MAFFESOLI, Michel.

(1996). No Fundo das Aparências. Petrópolis: Vozes, 1996.

MAGNANI, José Guilherme.

(2002). De perto e de dentro: notas para uma etnografia urbana". Revista Brasileira de Ciências Sociais, v. 17, n. 49, p. 11-29.

MOSCOVICI, Serge.

(2003). A representação social da psicanálise. 4 ed. Petrópolis: Vozes. 
MORIN, Edgar et alii.

(1997). A Sociedade em busca de valores: para fugir à alternativa entre o cepticismo e o dogmatismo. Lisboa: Instituto Piaget.

NIETZSCHE, Friedrich Wilhelm.

(2003). Humano, demasiado humano: um livro para espíritos livres. São Paulo: Companhia das Letras.

PETRAGLIA, Isabel Cristina.

(1995). Edgar Morin: a Educação e a Complexidade do Ser e do Saber. Petrópolis: Vozes.

ROBLES, Fernando Reis.

(2000). La ambivalencia como categoría sociológica en Simmel. Revista Española de Investigaciones Sociológicas. Disponivel em: http://www.jstor.org/discover/10.2307/401 84231 ?uid=3737664\&uid= Acesso em: 14 de agosto de 2014 .

SANTOS, Boaventura de Sousa.

(2007). Para além do pensamento abissal: das linhas globais a uma ecologia de sabere. Novos estud. - CEBRAP [online]. n.79, p. 71-94. Disponivel em: http://dx.doi.org/10.1590/ S0101-33002007000300004. Acesso em 20 de abril de 2012 .

SARACENO, Chiara.

(1997). Sociologia da família. Lisboa: Editorial Estampa, 1997.

SIMMEL, Georg.

(2006). A sociabilidade Exemplo de sociologia pura ou formal. In: Georg Simmel; Questões fundamentais da sociologia: sujeito e sociedade. Rio de Janeiro: Jorge Zahar.

\section{Recebido em}

outubro de 2015

\section{Aprovado em}

maio de 2016 